\title{
ENTREVISTA COM ROBERT LEVINE: A FALA DE UM HISTORIADOR BRASILIANISTA
}

Sonia Ranincheski

Durante os anos 60, em virtude da influência da teoria desenvolvimentista, inúmeros pesquisadores estrangeiros começaram a se dedicar ao estudo do Brasil e de outros países da América Latina. A maior parte desses estudiosos eram norte-americanos, embora houvesse outros de países como Canadá, Inglaterra ou França. Tais pesquisadores passaram a ser conhecidos como os brasilianistas. Um dos expoentes brasilianistas é Robert Levine, professor no Departamento de História da Universidade de Miami, onde é diretor do Centro de Estudos sobre a América Latina denominado de Latin American Studies desde 1989. O professor Levine pertence à geração de historiadores que iniciaram seus estudos durante a década de 1960, e ainda desenvolve pesquisas sobre nosso País, influenciando em nossa historiografia. Esta entrevista foi concedida pelo professor Levine especialmente para ser publicada na Revista Anos 90 Revista do curso de Pós-graduação em História da UFRGS.

S.R.: Desde a década de 1960, com a publicação Brazil: Field Guide in the Social Science, que o senhor vem se dedicando a pesquisar a história brasileira. O senhor poderia falar da sua trajetória de estudos sobre o Brasil? E ainda, em 1970, o senhor escreveu The Tilrgas Regime: the critical years -1934-1938, no qual procura compreender a história política e ideológica do Brasil através do papel político de Getúlio Vargas. Father ofthe Poor?: Tilrgas and his Era, publicado em 1998, é mais um dos seus livros em que novamente a figura central é Vargas. Como o senhor explica o legado de Vargas para a política brasileira?

R. Levine: Visitei o Brasil pela primeira vez em 1960, com um pequeno grupo da Universidade de Colgate, onde eu estudava no curso de graduação e que financiou os dez meses que passei na Argentina como estudante de intercâmbio. Vindo de Mendoza e Buenos Aires, paramos no Rio por um dia. Fiquei impressionado com a energia da vida da cidade, como nos bondinhos lotados de Santa Teresa ou na multidão vinda de Niterói que saía das barcas na Praça XV Dois anos depois, ingressei no pós-graduação em Princeton e estudei com Stanley J. Stein, que escrevera o rico e inovador estudo de Vassouras quando cursava o pós-graduação em Harvard. Depois de ser aprovado nas minhas provas em março de 1964 bastante abrangentes, pois o programa de Princeton 
incluía o conteúdo do mestrado -, fui admitido como candidato ao doutorado. Isto significava que eu poderia sair para pesquisar no meu maior campo de estudo, o qual, devido à influência do professor Stein, havia mudado da Argentina para o Brasil. Levando uma bolsa "generosa" da Fundação Ford no valor de US\$2.700,00 por ano, incluindo obrigatoriamente a compra da passagem de ida e volta, desembarquei no Aeroporto do Galeão apenas dez dias depois do golpe militar de 1964. Acabei ficando quinze meses, vivendo em quartos alugados em casas de família. Fiz também uma viagem de pesquisa para o nordeste (Recife, João Pessoa e Natal), de certa forma memorável; na volta, parei por quatro horas em Salvador para almoçar num restaurante baiano maravilhoso com vista para o mar da Barra.

Embora a repressão militar tenha se mantido razoavelmente moderada até 1968, sentiame, todavia, incomodado com o que acontecera, e percebi, desde o começo, que pesquisadores e estudantes brasileiros estavam preocupados. Os militares haviam fechado organizações estudantis atuantes e prendido esquerdistas conhecidos. Meus colegas estudantes estrangeiros (bem como amigos que eram voluntários do Corpo de Paz) tentaram manter-se neutros, embora a maioria de nós não simpatizasse com o golpe. Esta antipatia aumentou ainda mais depois que o governo de Castelo Branco abandonou sua promessa de livrar o Brasil da corrupção, concentrando seus esforços na erradicação do comunismo. Muitos, em 1964, não queriam que o Brasil se tornasse uma nova Cuba, mas a opinião pública internacional também não queria a repressão. Como editor do Field Guide to Research in Brazil, fiquei em contato com colegas pesquisadores e vi que eles também se sentiam preocupados com a cassação de direitos civis e com a agressividade dos anticomunistas e da extrema direita por parte dos civis que davam suporte ao golpe.

Quando percebi que pessoas haviam sido presas porque seus nomes estavam nas agendas de oponentes do regime ou porque elas tinham livros sobre a União Soviética em suas casas, ficou bem claro que o regime tinha um lado muito feio, especialmente no comportamento inconseqüente da polícia e de oficiais militares, freqüentemente agindo por conta própria. Seis anos mais tarde, por ser um adversário declarado da ditadura militar e membro de um grupo sediado em Nova Iorque que pro curava empregos e ajuda para exilados brasileiros (chamado de "O Palácio da Lua" devido ao restaurante chinês onde os integrantes se encontravam), fui classificado como personna non grata e não poderia viajar para o Brasil se precisasse de um visto. Mais tarde, com a abertura no final da década de 1970, isto terminou. 
A realidade do golpe forçou-me a deslocar o foco do meu estudo para outra época, trocando o período 1945-1947, no qual eu desejava trabalhar, pelos anos 30. Muitas das pessoas que eu queria entrevistar estavam na prisão ou relutavam em falar; assim, como uma medida prática, transferi o foco para o período anterior.

Após concluir e publicar minha dissertação pela Editora da Universidade de Columbia, recebi vários pedidos de firmas brasileiras para traduzi-Ia e publicá-la no Brasil. Por duas vezes, contudo, as traduções foram alvo dos censores brasileiros: na primeira, o manuscrito foi simplesmente rejeitado, e, na segunda, disseram que ele poderia ser publicado se o capítulo central, sobre as consequiências brutais das insurreições de 1935 , fosse removido. Com a nossa recusa, mais dez anos se passaram antes que a tradução brasileira fosse publicada pela Editora Nova Fronteira.

Naquela época, eu havia entrado em um projeto de pesquisa com dois colegas para estudar o papel dos estados dominantes na estrutura da federação brasileira de 1889 a 1937. O resultado foi a produção de volumes sobre Minas, São Paulo e Penambuco, tendo a Editora Paz e Terra publicado as traduções brasileiras. Meus projetos seguintes envolveram vários livros para referência, bem como algum trabalho sobre Cuba e também sobre a utilização de fotografias históricas e outras imagens como fontes para história social.

No começo dos anos 80, depois de conhecer e ficar cativado por José Carlos Sebe Bom Meihy, da Universidade de São Paulo, mudei o foco do meu trabalho. Fiquei interessado em "história oculta" (daí o porquê do meu livro sobre Canudos não se focalizar no papel de Euclides da Cunha ou no ponto de vista da elite, mas numa tentativa de entender por que um número tão grande de sertanejos vindos de vários lugares diferentes foram espontaneamente à cidade sagrada de Conselheiro). Fiquei também muito interessado em história oral, e, juntamente com José Carlos Sebe Bom Meihy, dei início ao projeto sobre a vida e o trabalho de Carolina Maria de Jesus, projeto este que já produziu nove livros sobre essa autora negra. Os royalties dessas obras são repassados aos netos de Carolina.

Há poucos anos, pediram-me que escrevesse um livro para a nova série da Universidade de Yale sobre a América Latina, editada por Stuart B. Schwartz e concebida para ser amplamente interpretativa e sintetizar novos conhecimentos. Tantos foram os trabalhos que surgiram a partir de 1966, quando completei minha pesquisa sobre Vargas, e tantas foram as fontes documentais que se tomaram disponíveis desde então, que decidi "revisitar" o assunto para verificar se minhas impressões sobre ele mudariam nesse 
período de trinta anos. A resposta é que ainda considero o papel de Vargas enigmático, e fico entristecido por sua demonstração de falta de sensibilidade pessoal, revelada pela publicação dos seus diários. Entretanto, acho que pelo menos para os moradores de cidades maiores, as reformas sociais de Vargas realmente formaram a base do Estado brasileiro com responsabilidade social que, bem ou mal, existiu até 1964. Apesar da promessa de Fernando Henrique Cardoso de desmantelar os programas de Vargas, penso que muitos deles serviram para permitir o acesso de membros da classe mais baixa a setores da classe trabalhadora e da classe média baixa. Um dos maiores defeitos de Vargas foi, contudo, seu desinteresse pela qualidade de vida dos moradores do interior rural. Essa falta, a meu ver, persiste entre muitos até hoje.

S.R: Durante as décadas de 1980 e 1990, foram produzidos inúmeros trabalhos de historiadores utilizando novas fontes de investigação, tais como o uso de imagens. Como o senhor vê o emprego desses recursos do ponto de vista da discussão historiográfica utilizada no seu livro The Brazilian Photographs of Genevieve Naylor: 1940-1943.

R Levine: Meu uso de imagens começou na década de 1960, quando, como fotógrafo amador, vendi para o New York Times algumas fotografias de turista para uma série sobre o aniversário de quatrocentos anos do carnaval. Depois que comecei a publicar livros, procurei usar imagens e fotografias não apenas para ilustrar, mas, também, como fontes de informação, principalmente de material cultural. Ministrei seminários em semiótica e sobre maneiras de observar as imagens, sendo que, no final dos anos 80, escrevi um livro publicado pela Editora da Universidade de Duke intitulado Images of History. A obra apresenta formas de ver fotografias da América Latina e de analisá-Ias pelo seu conteúdo. Infelizmente, esse livro não foi revisado de forma extensiva, nem publicado no Brasil. Além do livro de Naylor e de dois outros sobre fotografia, estou lendo, para posterior publicação, um livro (Editora da Universidade Rutgers) sobre os cubanos que emigraram para Miami (Cuban-Miami), que utiliza 180 fotografias e charges políticas para entender o impacto do influxo de quase um milhão de exilados cubanos para a cidade onde vivo. No ano passado, publiquei um livro interpretativo, Brazilian Legacies, no qual tentei olhar para alguns dos problemas atuais (impunidade política, pobreza urbana e rural, desigualdades raciais e econômicas) à luz de suas origens históricas, examinando formas pelas quais os brasileiros pobres aprenderam a lidar com sua condição. 
S.R: Recentemente Carlos Guilherme Mota afirmou que não há mais brazilianist, no sentido dos anos 60 e 80, mas especialista interdisciplinar, ou seja, não haveria mais especialistas em temas específicos de um país ou outro. (Revista Registro, v.5, n.9, mar./ago. 1998, p.9). O senhor concorda com essa afirmação?

R Levine: Acho que os "brasilianistas" mudaram com o tempo, mas principalmente por estarem mais bem preparados (em tradição cultural, história, economia, sociologia, ciências políticas e assim por diante) e com um melhor domínio da língua portuguesa. No meio universitário dos falantes de língua inglesa, há um deslocamento do que costumava ser chamado de "estudos setorizados" para a especialização em uma ou outra abordagem metodológica usando pessoas nativas de países estrangeiros como fontes para pesquisa.

S.R: E como o senhor vê o papel de associações interessadas no Brasil, como a BRASA, LASA e a Luso-Brazilian Review?

R Levine: Ao que me parece, a BRASA não obteve sucesso até o momento, pouco fazendo além de promover conferências; e até mesmo nelas, os brasileiros parecem estar segregados nas suas próprias mesas redondas - e os estrangeiros nas deles. Passei a não gostar da organização das conferências do tipo BRASA e LASA: papers entregues num período de tempo curto demais, participantes que não aparecem, sessões lotadas e ultrapassando o tempo previsto. Preferiria ver conferências menores mas com todos os papers distribuídos de antemão, permitindo que as sessões pudessem ser usadas somente para o debate. Eu também proibiria certas pessoas de distribuir essencialmente o mesmo paper repetidas vezes com apenas pequenas mudanças nos títulos. Não quero mencionar nomes, mas os leitores provavelmente conhecem pessoas que se encaixarão nessa descrição!

Quanto à LASA, embora eu seja co-presidente da seção sobre o Brasil, com mais de 250 membros, minha opinião é que ela sofre de muitos dos mesmos problemas da BRASA. Os encontros parecem circos, importantes pela oportunidade de intercâmbio - a meu ver -, mas inúteis em sua maior parte em termos de aprendizado. Isso muito se deve às centenas de mesas-redondas apresentadas uma logo após a outra durante todo o dia.

A Luso-Brazilian Review, da qual sou co-editor, seria um jornal melhor se recebesse mais manuscritos de acadêmicos brasileiros. E, se tivéssemos mais assinantes do que os atuais mil, poderíamos ter publicações mais de duas vezes por ano.

S.R Gostaria de lhe fazer algumas perguntas sobre as novas tendências da historiografia. Por exemplo, da França, surge uma tendência designada por Nova História Política, que 
seria dada pelo encontro da Nova História Cultural, que estuda as representações e os domínios do simbólico, com a História Política. Como o senhor vê este movimento? Como o senhor se posiciona diante deste campo que se abre com a "História do tempo presente"? Dentro dele, está a questão da globalização, fenômeno que tem sido discutido pelos historiadores e que se coloca dentro da nossa contemporaneidade do vivido. Como o senhor encara essas posturas?

R Levine: Sobre o assunto de novas metodologias, diria simplesmente que admiro muito mais aqueles novos campos baseados em pesquisa rigorosa (história ambiental, por exemplo, e história oral feita com bastante cuidado) do que os excessivamente teóricos e que se baseiam em novos tipos de definições. Se, em vez disso, estes tomassem como base a investigação histórica de informação, historiadores e acadêmicos poderiam propor novas idéias e interpretações. Alguns (mas não todos!) dos meus historiadores favoritos são George Mosse, Simon Schama, John Keegan, Boris Fausto, Warren Dean, José Murilo de Carvalho, Eduardo Silva, Jeffrey Lesser, José Carlos Sebe Bom Meihy, Marisa Lajolo e Linda Lewin.

S.R: Ainda dentro dessa última tendência, movimentos sociais que se apresentam entrelaçados com o político e que ainda estão em curso, como o Movimento dos Sem Terra, no Brasil, seriam objeto de trabalho do historiador?

R Levine: No meu ponto de vista, é eminentemente razoável para um curso de história de nível universitário começar, digamos, com a questão das bandeiras e monções, passar para Canudos e questões acerca da expansão das fronteiras do Brasil, e concluir com o Movimento dos Sem Terra. Em um curso que ministrei algum tempo atrás sobre a evolução da democracia brasileira, por exemplo, comecei com a Constituição de 1824 e terminei com o movimento das Diretas Já, que estava em curso na época. Hoje, quando tantas pessoas têm acesso à Internet, acho que é uma idéia interessante retirar material diretamente dela para ser usado pelos alunos; por exemplo, meu novo livro, The Brazil Reader (Editora Duke, junho de 1999) começa com o Brasil pré-Cabral e termina com várias cartas, histórias e reportagens da Internet e de jornais brasileiros não-elitistas.

S.R: Como o senhor vê a questão da interdisciplinaridade nos dias de hoje para os historiadores? O senhor acha que a história política vem ganhando com isso ou não?

R Levine: Acho que todos os pesquisadores devem ser interdisciplinares e que os acadêmicos devem, obrigatoriamente, ter uma ampla leitura em campos (bem como áreas geográficas e períodos de tempo) além do seu próprio. 
S.R: Finalmente, gostaria de agradecer a entrevista e pedir que o senhor fale sobre o seu projeto de longo prazo chamado História oral sobre a cidadania brasileira.

R Levine: O projeto de história oral sobre a cidadania precisa ter alguns de seus aspectos de pesquisa iniciais redefinidos. É muito difícil, como acabamos por descobrir, trazer à baila tipos de perguntas que encorajem os entrevistados a responder de maneiras originais. Um dos objetivos mais importantes do projeto de cidadania (consulte o endereço www.as.miami.edu/las para a descrição do projeto e de seu questionário atual) é pesquisar as opiniões sobre as responsabilidades e direitos dos cidadãos brasileiros em todo o País, não apenas nas cidades principais. Freqüentemente, livros e artigos sobre o Brasil falam predominantemente de São Paulo, Rio, Recife ou Belo Horizonte. Talvez a Internet nos dê acesso a um maior espectro de informações e idéias. 